\section{The mentally ill in prison}

Dear Sirs

The recent case of a mentally ill remand prisoner found hanging in a cell at Brixton Prison draws our attention yet again to the mentally ill in our prisons. Following this case the coroner made five recommendations. One was that Brixton needs to review their allocation of prisoners requiring medical examination, a need highlighted by recent Home Office guidelines (Home Office Circular No. 66/90) in which they advise treatment of abnormal offenders be a priority area and that individual authorities audit their practice and ensure an adequate service is provided.

A study of the probation service has been carried out in Nottingham. A questionnaire, completed anonymously by 30 probation officers in the Nottingham area, focused on three main areas: the criteria used to select clients; the procedure for obtaining a report; and ways in which the present system could be improved.

The decision to refer for a psychiatric opinion was a difficult one for the majority (17 out of 30 ). The reasons for referral were: people are at risk because of client's abnormal behaviour (19 out of 30$)$; client not fit to appear in court (18 out of 30 ), so the case could be adjourned awaiting a full psychiatric report (12 out of 30); to enable more appropriate treatment and care early on (22 out of 30 ); to obtain advice on disposal ( 9 out of 30 ).

There was general agreement on criteria for referral: nature of offence (14 out of 30 ); past psychiatric history ( 20 out of 30 ); abnormal behaviour ( 22 out of 30); intuition ( 18 out of 30 ). One out of 30 said they did not know what criteria to use for referral. Twenty-three out of 30 probation officers did not think that they were adequately trained to decide who to refer and 18 out of 30 did not know the procedure for obtaining a psychiatric opinion should one be needed.

Suggestions were made as to how the system could be improved, including a formalised education programme as part of the in-service training requirements and improved liaison between the legal system and psychiatric services.

This is a preliminary study and the low numbers involved must lead to cautious interpretation of the findings. However, the results highlight important deficiencies in training and in liaison between the courts and psychiatric services, and the need for a more comprehensive survey of the whole Probation Service. A more 'active' approach is needed on both sides for the mentally ill to be recognised as early as possible and removed from the criminal justice system.

Queen's Medical Centre

Mary Hamlton Nottingham NG7 $2 U \mathrm{H}$

\section{Adolescent psychiatry experience for psychiatry trainees}

\section{Drar Sirs}

Specialised services for children were not available until the early 1920s when the first clinic, the East London Child Guidance Clinic, was opened. Separate services for adolescents were established in the late 1940s. Slow expansion took place, with adolescent special out-patient clinics appearing in the late 1960s. There followed further expansion, with provision for day patients, links with hostels and approved schools.

More recently, the College (1983) has recommended a minimum of two consultants per 200,000 of the population. It also recommends (1990) that there should be a significant element of experience in child and adolescent psychiatry at registrar level, either part-time or whole-time. The $4 \frac{1}{2}$ to 5 years training scheme must include a placement (minimum of six months) in child and adolescent psychiatry or mental handicap and psychiatry of old age.

The above guidelines are in line with the recommendations of the NHS Health Advisory Service (1985) on services for disturbed adolescents, which proposes that all trainee psychiatrists should have a general introduction to child and adolescent psychiatry and that trainees in child and adolescent psychiatry should have adequate training in adolescent psychiatry.

Given the range of subspecialties available to the psychiatric trainee, one must consider the arguments for devoting a placement to adolescent psychiatry. Adolescent psychiatry is still not widely developed, and it is therefore important for its future that junior doctors are not only exposed to this option for their future career but also gather the understanding required to plead for adolescent needs within each psychiatric service. There are particular aspects of adolescent psychiatry that provide unique insights which can enhance future understanding of adult patients. Adolescents are at the stage of passing between childhood and adulthood and the problems they present may have origins in childhood, as in dealing with difficult behaviour following a disrupted family life-style, or be early expressions of illnesses that usually appear in adulthood (e.g. schizophrenia). Whatever the problem, there is always a tension between the adolescent's bid for independence and his/her rootedness within a family or substitute family.

In adolescent units, developmental issues of growth, sexual, intellectual, and family changes are not historical events, as they are for many adult psychiatric patients. They are visibly in the 'melting pot'. This provides opportunities for preventive work, allowing the trainee the opportunity to work with families, schools and other institutions, in often 
well supervised situations. It also helps the understanding of adult patients' descriptive histories. Knowledge of developmental, family and service interaction issues can allow trainees to reappraise the context of the histories of adult psychiatry patients, not only of those patients' adolescence but also of the situations in which the patients now find themselves.

Despite College recommendations, many trainees may not have the opportunity to complete their training by having worked with children or particularly with adolescents as a specialist placement.

ARTURO LANGa

Leavesden Hospital

Abbots Langley

Watford WDS ONU

\section{References}

HAS (1985) Bridges over Troubled Water. Sutton: Health Advisory Service.

Royal College of Psychiatrists (1983) Providing a district service for child and adolescent psychiatry: medical manpower priority? Bulletin of the Royal College of Psychiatrists, 7, 94-97.

(1990) A statement on approval of training schemes for general professional training for the MRC Psych. Psychiatric Bulletin, 14, 110-118.

\section{Malignant alienation - agent and host interaction? \\ DeAr Sirs}

Morgan \& Priest (1984) coined the term "malignant alienation" when describing patients who had committed suicide while receiving in-patient care or shortly after discharge. A theme of inexorable alienation had been evident in many cases, whereby ward staff became critical of the patient's behaviour. Behaviour was construed as provocative, unreasonable and over-dependent. In some cases disability was thought to be deliberately assumed. The process was malignant because of the relentless drive towards a fatal outcome. The authors felt that malignant alienation might be provoked by recurrent relapses or difficult behaviour-problems arising from the patient. These patients committed suicide, but did they truly kill themselves?

Who are these "difficult" patients, and how might health care professionals react to them?

The characteristics of such patients might be summarised as follows. Patients who do not improve with treatment, those who present challenging behavioural problems, and those where a clear diagnosis and/or treatment plan is lacking.

Health care professionals should be aware of their own attitudes and feelings to all patients, but particularly those engendered by difficult patients. There may be many staff whose own neurotic blindspots actually prevent the giving of appropriate care. For example, the doctor who habitually undertreats patients for fear of hurting or upsetting them. The nurse who over-identifies with an aspect of the patient and tends to be overly optimistic about the clinical outcome, or alternatively becomes irritable with the patient when progress is slow. The doctor who feels that a poor response to his treatment is a personal insult, who then uses dangerous or unwarranted treatments in an attempt to salvage his pride. Such interactions become even more testing with difficult patients. Surely the lesson to be learned is to become more aware of our own responses when dealing with patients? This self-observing quality is a most important attribute.

Sir Denis Hill put his finger on another crucial attribute. In defining the requisites for a good psychiatrist he included "protection of the patient from the negative aggressive aspects of one's self" (Hill, 1978). But what is this negative aggressive aspect?

Aggressive instincts are generally now seen as being directed outwardly and are not necessarily negative. Indeed, these instincts may be part of a biological inheritance which serves to preserve us. In this way aggression is seen as the basis for human achievement and mastery in the world, valuable in the process of differentiation and personal autonomy. The complexities, hierarchies and conventions that form the framework of society may have evolved as a defence against negative aspects of aggression, ensuring cooperation and the survival of the species rather than allowing unrestrained inter-personal destruction (Storr, 1968).

Is an awareness of the negative aspects of outwardly directed aggressive impulses useful when considering malignant alienation?

Not long ago a staff nurse from the psychiatric ward telephoned me. She was distressed and upset. A patient had just gone AWOL from the ward and she feared for his safety. We talked it over. She had alerted the patient's family and general practitioner, and informed the police. I knew that this nurse was level-headed and usually coped well with such incidents. What was so different now? I went over to the ward to see her. It became clear that the patient had been "difficult" that day, threatening staff and pushing them to their limits. This was compounded by staff shortages through sickness. Under considerable stress this nurse had wished the patient dead. The feeling was conscious momentarily, and was only a fantasy, but it had occurred. So when the patient finally absconded the nurse felt her own murderous feelings had played their part, and she feared greatly for his life.

Can a synthesis be achieved here? Malignant alienation may be the harbinger of suicide with difficult patients. Staff feelings could play a part in fueling the process. Negative feelings towards the patient initially lie hidden. With further adverse interaction these feelings may tumble briefly into 